\title{
Georges Bataille e Divinus Deus ${ }^{1}$
}

(Georges Bataille and Divinus Deus)

(Georges Bataille y Divinus Deus)

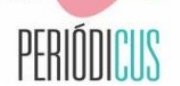

ISSN: 2350-0844

п. 14. v. 1 nov.2020-abr.2021

Yukio Mishima p. 229-241.

Tradução:

Renan Kenji Sales Hayashi ${ }^{3}$

RESUMO: Este manuscrito apresenta uma tradução de um texto do escritor japonês Yukio Mishima, em formato de prefácio, escrito em 1970, sobre duas obras literárias do autor francês Georges Bataille. No prefácio, Mishima faz a apreciação dos escritos de Bataille, destacando o aspecto do erotismo e do valor da transgressão de aspectos religiosos - eminentemente cristandade ocidental - na literatura. Para Mishima, a experiência da leitura de Bataille, ao colocar Deus sob a forma de uma prostituta lasciva e manifesto em um episódio de incesto entre mãe e filho, sentenciam o escrito de Bataille para além da narrativa clássica tão comum no século XX. Por ser um texto raro e de extrema importância tanto para os estudos literários, quanto para a fortuna crítica de ambos autores, empreendemos o gesto tradutório como forma de prover (sobre)vida ao escrito que, por si só, já demonstra sua irrefutável relevância histórica, literária e cultural.

PALAVRAS-CHAVE: Yukio Mishima; Georges Bataille; Literatura Japonesa; Literatura Francesa; Erotismo.

\begin{abstract}
This paper presents a translation of a text by the Japanese writer Yukio Mishima, in a preface format, written in 1970, about two literary works by the French author Georges Bataille. In the preface, Mishima appraises Bataille's essays, highlighting the aspect of eroticism and the value of transgressing religious aspects - eminently Western Christianity - in literature. For Mishima, the experience of reading Bataille, when considering God in the form of a lustful prostitute and manifested in an episode of incest between mother and child, sentenced Bataille's writing beyond the classic narrative so common in the 20th century. Due to begin a rare and extremely important text, both for literary studies and for the critical acclaim of both authors, we undertake the translation gesture as a way of providing (long-term-)life to the writing that, itself, has already demonstrated its irrefutable historical, literary and cultural relevance.

Keywords: Yukio Mishima; Georges Bataille; Japanese Literature; French Literature; Eroticism.
\end{abstract}

Resumen: Este manuscrito presenta una traducción de un texto del escritor japonés Yukio Mishima, en un formato de prefacio, escrito en 1970, sobre dos obras literarias del autor francés Georges Bataille. En el prefacio, Mishima evalúa los escritos de Bataille, destacando el aspecto del erotismo y el valor de transgredir los aspectos religiosos, eminentemente cristianos occidentales, en la literatura. Para Mishima, la experiencia de leer Bataille, al poner a Dios en la forma de una prostituta lujuriosa y manifestarlo en un episodio de incesto entre madre e hijo, sentenció la escritura de Bataille más allá de la narrativa clásica tan común en el siglo XX. Debido a que es un texto raro y extremadamente importante tanto para los estudios literarios como para la fortuna crítica de ambos autores, emprendemos el gesto de

1 Optamos por deixar o título em latim por dois motivos: no texto original de Mishima, o título foi deixado na língua latina por fazer referência à obra de Bataille, organizada sob a referida inscrição. Além disso, o uso da língua portuguesa e do latim imprimem efeitos de sentido significativos na dinâmica do gesto tradutório, como se verá ao longo do texto (N. do T.).

${ }^{2}$ Pseudônimo literário do escritor japonês de Kimitake Hiraoka (1925-1970).

3 Docente na ESAMC/Campinas. Doutorando em Linguística Aplicada na Unicamp. Mestre em Linguística Aplicada pela UnB. Tradutor. 
traducción como una forma de proporcionar (sobre)vida a la escritura que, en sí misma, ya demuestra su irrefutable relevancia histórica, literaria y cultural.

Palabras clave: Yukio Mishima; Georges Bataille; Literatura japonesa; Literatura francés; Erotismo.

\section{Apresentação}

Mishima leitor de Bataille. Japonês leitor de francês. Mishima com Bataille. Mishima versus Bataille. Em uma primeira investida, parece um tanto improvável que um escritor como Yukio Mishima (1925-1970) pudesse se apropriar profundamente de escritos de autores do mundo ocidental, em especial, aqueles cuja audácia e erotismo contrariavam a ética e o recato do típico japonês recém-saído de um país com quarenta e cinco anos de isolamento, como foi o Japão, durante a Era Meiji (1868-1912).

Contudo, Mishima passava ao largo de preencher os requisitos do imaginário social do japonês contido e dedicado ao coletivismo. Ao contrário, tendo uma vida altamente interessante, com um desfecho não mesmo atrativo - seppuku, suicídio horando aos moldes dos samurais, cortando o ventre o pescoço com uma espada - não é de se estranhar que ele tenha tido fascínio pela obra de Georges Bataille (1897-1962). O autor que consagrou o erotismo na literatura, também abriu espaço para o pensamento do erotismo como uma forma de ser e existir, fazendo do excesso e da sujeira moral - condenados na ética cristã do pastorado - fosse visto por outros prismas por leitores do mundo inteiro, entre os quais estava o também escritor Mishima. Mishima, não só compartilhava da mesma profissão que Bataille, como também esteve na França e estudou detidamente a literatura francesa, assim como muitos de seus compatriotas também escritores, como Yasunari Kawabata (1899-1972) e Kobo Abe (1924-1993).

O estudo dos escritos franceses possibilitou a Mishima a atuação não só como estudioso da temática, mas também como ensaísta e crítico literário, sendo endossado por sua graduação em Direito pela Universidade Imperial de Tóquio. Com efeito, pode-se dizer que o fato de Mishima não partilhar de um contexto social e cultural embebido da moral e da ética cristã - as religiões mais proeminentes no Japão eram o Budismo e o Xintoísmo à época - trouxe benefícios a ele na abordagem da obra de Bataille. Tal abordagem não ficou restrita ao papel de leitor, como se poderá ver na tradução ora empreendida, que trata de um prefácio que Mishima escreveu para a edição japonesa das obras de Bataille Madame Edwarda e Minha Mãe - organizadas sob o título de Divinus Deus -, cujo teor afronta definitivamente qualquer substrato religioso que assume a trindade e a Virgem Maria como os epítomes sagrados e impassíveis à profanação. Pelo contrário, vemos em Bataille, apreciado por Mishima, que nos referidos escritos, Deus 
assume a forma de uma prostituta lasciva que se declara divindade nos momentos exatos dos intercursos. Além disso, também em Bataille, se vê que a forma de Deus se manifesta naquilo que parece ser mais interditado: um episódio de incesto entre mãe e filho, diante da morte do genitor, que assume o caráter de nome-do-pai lacaniano perdido para sempre.

À vista disso, Mishima aprecia as obras de Bataille em seus valores estético e literário, pontuando o que há de inovador nas linhas do autor francês, sem deixar de lado os pontos em que este escorrega e cai no preciosismo da narrativa literária clássica e um tanto previsível. Mishima, em seu prefácio, estima o que é revelador da obra de Bataille como escritor: o gosto pela transgressão. Transgressão essa que também está muito presente nas obras do próprio Mishima, a começar por Confissões de uma máscara (1949), cuja temática homossexual rompeu em definitivo com o caminho das narrativas centradas no eu - chamadas Shishosetsu na fortuna crítica japonesa. Assim, Mishima adiciona uma camada a mais no sujeito contado na literatura japonesa: o sexo entre homens.

Entretanto, essa transgressão não se restringe somente a essa obra. Dezenas de outras, produzidas em sua curta, porém extremamente profícua carreira de escritor, questionam as posições naturalizadas do ser humano e colocam o erotismo e o sexo nos lugares onde eles pareciam impensados. No conto Patriotismo (1966), que muitos biógrafos afirmam ser uma espécie de epitáfio - descrevendo como seria seu próprio suicídio no futuro - que, diga-se de passagem, guarda muitas semelhanças reais - Mishima se mostra muito investido da aura de erotismo, descrita por Bataille, quando envolve a cena de suicídio de um casal de japoneses com ricas passagens eróticas. O marido, do exército imperial, ela, esposa devota e obediente, realizam cada qual sua cena de tirada da própria vida, após uma tórrida cena de sexo. Porém, como vemos em Bataille, o erotismo não está propriamente no sexo, mas no ritual de suicídio, na estética do silêncio que precede o fim, nos interditos morais que colocam ele e ela frente a frente com a díade vida-morte, embebidos sangue que jorra semelhante ao excesso de humores de que a vida biológica necessita.

Nesse sentido, não se configura exagero afirmar "Mishima leitor de Bataille”, exatamente pelo fato de encontrarmos transpirando nas linhas do escritor japonês o excesso de humanidade de que Bataille tanto se esforçou por conceituar. A vitória do grotesco sobre o sublime; da sujeira moral contra a elevação espiritual; da depravação do corpo como o alcance do etéreo. Dito de outra forma, é lendo Bataille versus Mishima que poderemos compreender ambos, na medida em que vemos no francês o centro gravitacional de uma teoria que estrutura o não-dito, o maldito e o 
interdito na estética do romance e da escritura. Todavia, é no escritor japonês que podemos ver uma interlocução do ensejo teórico batailliano elevado à ultima potência, como se Mishima tivesse enxergado no erotismo de Bataille as possibilidades literárias que o próprio autor negligenciou não fortuitamente.

À vista disso, a tradução desse prefácio escrito por Mishima sobre as obras de Bataille, Madame Edwarda e Minha mãe, se configura como um gesto de trazer para a língua portuguesa do Brasil um escrito que represente todo esse movimento de interlocução de realidades diferentes Japão e França. Mas também pode representar a possibilidade de fazer borda na memória de autores cujas obras são, a um só tempo, distantes e vizinhas. Seja pela temática, seja pela compreensão do valor da literatura como espaço de representação da vida em suas mais diversas óticas.

Ressaltamos que este texto, embora esteja em domínio público, até pelo tempo de escritura, 1970, caiu em um esquecimento, o que o tornou simultaneamente raro e preci(o)so, tanto para a fortuna crítica da literatura japonesa, quanto para a literatura francesa e seus desdobramentos nos escritos que se produziram na modernidade ocidental e oriental. De tal modo, vemos em nosso gesto tradutório uma forma de dar uma (sobre)vida à preciosidade que é um texto de um autor como Mishima escrevendo sobre uma figura de destaque como foi Bataille. Nesse sentido, na (sobre)vida e na profusão que é a babel das línguas, esperamos contribuir para o não-esquecimento daqueles que, em vida, foram uma explosão de libido e pulsão de morte. Daqueles cujos escritos pulsam na díade vida-morte e fazem garantir na tradução a possibilidade de atingir vários públicos, ora chocando-os ora seduzindo-os. Assim, fazer da vida interditada diária uma fenda aberta na e pela literatura. E por meio desta fenda mesmo, constituir borda onde só a linguagem alcança. Não qualquer linguagem, mas, sobretudo, a erótica, cujo excesso e transbordamento fazem do humano - demasiadamente humano - tanto refém quanto criminoso, autor e leitor, escritor e tradutor, amante e admirador. Enfim, operando no excesso que comanda a vida, mesmo quando dela, o erotismo pareça prescindir.

\section{Tradução}

Recentemente, li dois romances extremamente elevados e devo escrever sobre eles aqui, pois o vívido efeito resultante de lê-los parecia incomparável ao de qualquer outra coisa.

Eles foram chamados Madame Edwarda e Minha Mãe, de um livro intitulado Divinus Deus, de Georges Bataille. No passado, os leitores japoneses de Bataille eram 
acometidos por traduções ruins. Desta vez, no entanto, a tradução de Kosaku Ikuta resultou em algo claramente melhor.

Os escritores que presto mais atenção na literatura ocidental moderna são Georges Bataille, Pierre Klossowski e Witold Gombrowicz. Isso ocorre porque em suas obras pode ser encontrada uma conexão vívida, dura, chocante e imediata entre a metafísica e a carne humana, que formam um elo direto entre os séculos XVIII e o XX, ultrapassando o século XIX. Essas obras revelam um delineamento antipsicológico, um antirrealismo, um intelectualismo erótico, um simbolismo direto e uma percepção do universo oculto por trás de tudo isso, além de muitas outras características comuns.

Madame Edwarda, de Bataille, é um romance que demonstra a manifestação de Deus ao homem e é, ao mesmo tempo, uma obra extrema em sua obscenidade. O narrador paga à Madame Edwarda, uma prostituta que se intitula de Deus, no prostíbulo 'The Mirrors'. Ele, então, a segue quando ela sai usando uma capa preta cobrindo seu rosto e seu corpo nu. Ele testemunha o ataque repentino de Edwarda e a ajuda a entrar em um táxi, onde ele vê uma manifestação do verdadeiro Deus em Edwarda, que se senta em cima do motorista de táxi e copula com ele.

Quando lida junto com Minha Mãe, deve-se notar que a imagem da mãe se sobrepõe à de Edwarda, e com ela uma visão de contaminação, de incesto que viola a santidade da Sagrada Mãe. Mas, nessas obras, a Mãe Sagrada não sofre passivamente como vítima de transgressão; ela mesma estimula os outros e os força a uma experiência cheia de terror, repulsa e êxtase, que os leva a testemunhar a Deus.

No entanto, meu objetivo aqui não é desenvolver uma teoria sobre Bataille. Eu tenho muitas coisas que gostaria de dizer sobre Bataille neste espaço limitado.

O que é certo, no entanto, é que, estando ciente de que a qualidade sagrada escondida na experiência do erotismo é algo impossível de ser alcançado pela linguagem (isso também se deve à impossibilidade de re-experimentar algo através da linguagem), Bataille ainda a expressa em palavras. É a verbalização de um silêncio chamado Deus. E também é certo que a maior ambição de um romancista não poderia estar em nenhum outro lugar, exceto aqui. Uma mulher foi escolhida para representar Deus, que aparece no romance através da unidade essencial do espírito e da carne incorporada na mulher. E o reconhecimento de que a mãe (pensada para 
representar a maior virtude da mulher) e a prostituta (pensada para representar o mais imundo) ambas se originam da mesma parte dessa carne: você pode se lembrar das palavras de Baudelaire, que chamou Deus de representante das prostitutas.

É uma tarefa impossível apreciar Bataille de uma maneira comercial com essas interpretações intelectuais, mas para ler este romance (especialmente o texto traduzido!), é necessário supor que o que fica é apenas a parte que conseguiu romper os limites da linguagem.

No prefácio, Bataille diz: "Se não há nada que ultrapasse nossos poderes e nossa compreensão, se não reconhecermos algo maior que nós mesmos, maior do que somos apesar de nós mesmos, algo que a todo custo não deve ser, então não o fazemos, alcançar o momento insensato para o qual nos esforçamos e que ao mesmo tempo exercemos todo o nosso poder para evitar'.

Esse “momento insensato” é - escusado dizer -, o momento em que Deus - grotesco e medroso - aparece.

“ [...] a existência em nós, durante esses interlúdios, existe apenas por um excesso sustentador e ruinoso, quando a plenitude do horror e a da alegria coincidem ... O que - deixando de lado a representação do excesso - a verdade significa se não vemos que o que excede as possibilidades da visão, aquilo que é insuportável ver como, em êxtase, é insuportável conhecer o prazer?"

Um modo de pensamento cristão muito típico é evidente na ideia de Bataille de que, em suma, Deus não se manifesta enquanto nosso ser permanece em sua forma adequada e equilibrada. Somente quando nossa existência exceder essa vida e deixar para trás algo, como os contornos das pessoas deixadas nos degraus de pedra de Hiroshima, depois que a bomba atômica foi lançada, Deus se manifestará. O que é único é sua utilização do 'erotismo e da dor' ao extremo como forma de alcançar a Deus.

Madame Edwarda começa com um parágrafo simples, apresentando o narrador, um bêbado lascivo e muito típico. Tendo testemunhado 'duas prostitutas furtivas descendo a escada de um mictório', o narrador, assombrado pela luxúria e pela angústia, começa a tomar bebidas de um bar para outro, à medida em que o dia passa. Esta introdução termina em seis linhas. 
A história muda repentinamente no parágrafo seguinte. O bêbado, que não conseguia controlar o desejo de "ficar nu como a noite", tira as calças na rua para "segurar meu pênis ereto".

O que está para acontecer? De repente, as regras do mundo caem junto com as calças dele. Com velocidade assustadora, a história leva o narrador ao prostíbulo 'The Mirrors', que o leva a conhecer a prostituta, Madame Edwarda.

A simplicidade verdadeiramente francesa é abundante na descrição - tonta, como se estivesse subindo uma escada em espiral - de levá-la ao seu quarto, advinda da multidão consumida pela embriaguez torpe, pela provocação sexual e por intercursos. A mulher, tendo levantado uma perna, puxa a pele das coxas com as duas mãos e mostra sua 'fenda cabeluda e rosada, tão cheia de vida quanto uma lula repugnante'. Em seguida, se declara sendo DEUS. Todas essas descrições, por sua simplicidade, velocidade e densidade, são elegantes. A elegância, no que diz respeito à literatura, não passa de uma postura direta. (Lembro-me, com interesse, das críticas de Fumiyo Enji a Erojishitachi, de Akiyuki Nosaka, onde ela a descreveu simplesmente com a palavra "elegante".) E, seguindo o ritual da prostituta de "a dama ascendendo", Madame Edwarda se levanta entre desordens e loucuras, com uma dignidade e esplendor quase trágicos, que nos lembram a técnica de Jean Genet de glorificar a sujeira. É sem dúvida uma "consagração real".

Agora, este pequeno romance pretende ser um testemunho horrivelmente simples da existência de Deus. Em sua estrutura, está tecido um sentimento de suspense, como em um thriller: quando Deus se manifesta ao homem? E quando é confirmada a existência de Deus? Tudo é construído com muito cuidado, como se fosse uma peça de um ato. Na primeira cena onde o narrador encontra Madame Edwarda, dorme com ela e persegue a mulher, que se vestia apenas com uma capa preta sobre seu corpo nu e vagava repentinamente - o narrador ainda não alcançou a experiência de testemunhar a Deus. Embora a própria Edwarda tenha o nome de Deus, a prova da existência de Dele ainda é omitida.

Então, quando o narrador vê Edwarda de preto, de pé sob um arco, "tão angustiante quanto um vazio, um buraco", ele, que, por uma descarga sexual, se liberta e, portanto, livre de intoxicação, reconhece que Edwarda, como ela mesma declarava, é DEUS.

Pode-se argumentar, no entanto, que este é de fato um Deus teórico, um Deus cartesiano que foi alcançado através do intelecto despertado da luxúria sensual, através de uma iluminação. 
Este é, de certa forma, o truque desse romancista engenhoso. Além disso, nesta cena central, o escritor deixa uma mulher vestida de preto e com uma máscara percorrer a grande cidade deserta tarde da noite e cria uma atmosfera misteriosa, tão completamente diferente da cena anterior, como para convidar o leitor a um templo gigantesco. Aqui Edwarda, de repente, convulsiona e expõe seu corpo branco e nu, se contorcendo em um espasmo, na frente do narrador e do leitor, como uma fenda branca na escuridão.

É o narrador que está assistindo: é o narrador que passa, com uma espécie de ansiedade fria, o tempo que muda pouco a pouco, dentro do nada a ver, como a areia em uma ampulheta, a essência da própria existência em direção a um objeto. Ela chama z si mesma de Deus e o narrador também a reconhece como DEUS. É nesse tempo que Deus pode ser visto. Quando Ele aparecerá? Antes destes desespero e angústia, e do espasmo no corpo branco e nu de Edwarda (que é a manifestação física de ambos), o narrador quase toca a fenda entre suficiência de ser e excesso de ser, mas nunca completamente ...

Mas...

"Algo se agitou em meu grande desespero."

"O êxtase desidratante da febre estava saindo da minha total incapacidade de me controlar."

\section{“Ecstasy” é novamente necessário!}

Portanto, o narrador cai de uma representação, até agora, quase matemática para uma de perturbação. As palavras são rejeitadas e ele fica preso em uma luta - "eu escreverei em vão". Esse comentário sobre o impossível, sua inacessibilidade através da linguagem, não é um mero ponto final do romance, mas constitui um sub-enredo para a experiência erótica de testemunhar Deus na última cena.

O romance atinge seu verdadeiro clímax em um táxi na cena final. A cena do intercurso com o motorista de táxi consiste em aproximadamente dez linhas, nas quais há um vislumbre do abismo mais sombrio da existência humana, ao mesmo tempo em que há o domínio do crepúsculo puro e claro que surge a partir daí. Aqui Bataille mostra uma força de impacto como romancista, que momentaneamente encanta. 
A palavra "Deus" não é mais usada explicitamente. O narrador alcança o abandono, recusa a visão e confessa "minha própria angústia e febre pareciam pequenas coisas para mim". Mas, então, Deus, de fato, se manifesta naquele exato momento, e torna-se certo que o narrador o viu.

Madame Edwarda é de fato um romance peculiar. Embora possa parecer um trabalho arbitrário e indisciplinado comparado a, por exemplo, um romance clássico, como o Prosper Mérimée, de Matteo Falcone, há uma estrutura clássica estrita oculta dentro dele, se você o ler com atenção. Você percebe que a intensidade de asfixia fermenta como resultado de uma composição tão clássica.

Minha Mãe, de Georges Bataille, é uma obra de tamanho médio que assume a forma com uma completa mudança de Madame Edwarda - de um clássico francês de romance psicológico. De fato, isso continua sendo uma mera forma e, com Minha mãe, aprendemos que Bataille é um escritor proficiente nessas técnicas clássicas de romancistas comuns. Embora ele pudesse facilmente se contentar com essas técnicas, ele, ousadamente, não encontrou interesse em nada além dos mesmos assuntos que minam as raízes mais profundas nas quais essas técnicas são fundamentadas. É assim que, como resultado, ele se torna para o leitor um autor extremamente exigente, mas recompensador.

O narrador era um jovem de dezessete anos quando seu pai morreu. Era 1906. Ele odiava o pai - que, embriagado, costumava atormentar a esposa - e chegou a considerar entrar na Igreja como uma revolta contra seu anticlericalismo. Finalmente, porém, ele desiste da ideia de se tornar padre para viver com sua mãe: ela é sagrada para ele, e ele a adora.

Até então, aos olhos do menino, sua mãe era uma vítima triste e inocente do pai tirânico: ele, dominado pela bebida, pelas mulheres e pelo jogo; ela, um ser bonito e doce que chama seu filho de 'meu galante amante'. Até aquele momento, o garoto apenas desejava ser seu cavaleiro perfeito. Até agora, uma história comum, e o começo simples consiste em vários parágrafos eloquentes que, embora despidos de retórica, ainda são bastante requintados.

O menino estava ciente do hábito secreto de beber da bela e triste mãe, mesmo quando seu pai ainda estava vivo. Mas com a morte do pai, a imagem da mãe é radicalmente transformada. Ela confessa inesperadamente que é ainda pior que o pai: "Seu sorriso horroroso e perturbado era o sorriso de aflição". 
A vida inteira do garoto, para surpresa dele, dependia de conspirações "inventadas" pela solicitude dos pais. "Mais tarde, ela emprestou uma frase do meu pai. 'Apenas coloque a culpa por tudo em mim' Esse era o desejo dele, entendendo que, aos meus olhos, minha mãe estava além da censura e deve, a todo custo, continuar assim".

A verdade é gradualmente revelada. No final, sua mãe comete suicídio. Aqui estão as palavras dela, que poderiam ter sido seus votos: "O que eu quero é que você me ame até a minha morte. De minha parte, é na morte que eu te amo neste exato instante. Mas não quero o seu amor, a menos que você saiba que sou repulsiva e me ame como você o conhece".

Essa história que, como um clímax dessa perversão e loucura, termina em uma cena de incesto sagrado em que a espiritualidade é revelada. É uma cena que só posso deixar para o leitor apreciar. Mas, para mim, seria certo que esse trabalho conseguisse satisfazer uma sede que nenhum romance japonês recente poderia atenuar.

À medida que a verdade sobre a mãe do menino é exposta, a escrita de Bataille deixa o estilo suave e moderado que foi mantido até então. E, como para provar que as paredes desta confortável casa, que pareciam tão estáveis, eram de fato apenas feitas de papelão, ele estica uma lâmina afiada atrás da outra e continua rasgando em excesso de brutalidade.

"Quero ver desprezo em seus olhos, desprezo e medo". Esse foi o último desejo expresso pela mãe, tanto como mãe, quanto como mulher. Corromper alguém é despertá-lo para a verdade, e ela deve ser a personificação dessa verdade - a verdade que ela adere - e não seu porta-voz: em suma, ela tem que ser, em última instância, o próprio "Deus". Essa é provavelmente a estrutura fundamental dos romances de Bataille e, às vezes, eu detecto os restos de um deísmo do século XVIII em Bataille. Restos dos quais levam a mãe a dizer: "É apenas na devassidão que me sinto mais lúcida".

O que é esse amor sincero que a leva a permitir que outros - além de seu amado filho experimentem uma visão de Deus? Ela, discípula de Safo?

Para nós, ler um romance é uma experiência meio sensual, meio intelectual e investigativa. A esperança e a ansiedade - "O que vai acontecer? " - e a esperança de uma solução para as perguntas de 'por quêe?' 'para quê?' 'quem?'. Esses são os desejos ingênuos e fundamentais de quem se entrega a ler romances, qualquer que seja sua qualidade. $\mathrm{O}$ Bildungsroman costuma usar a primeira pessoa, pois essa voz é a mais fácil de comunicar 
sensações ao leitor. É o gênero em que o leitor se identifica com o herói e que, despertando a curiosidade intelectual do leitor e sua vontade de conhecer, os faz refazer em um curto período todo o processo pelo qual o herói se desenvolve - que, na realidade, é esticado por muitos anos.

Os romances de Bataille enfrentam essa concepção - eles podem ser chamados de educação em corrupção -, mas as estruturas fundamentais dos dois são muito semelhantes. $\mathrm{Ou}$ seja, este é um romance concebido para que o narrador represente o desejo de investigação ingênuo do próprio leitor, seu desejo de analisar intelectualmente, sua autoconsciência, seu lirismo, seu desejo sexual, etc. Assim, o leitor, como resultado inevitável desses desejos, é forçado a encarar a verdade, a verdade que ele jamais desejaria ver, mas não poderia mais evitar, e, apenas passando por esse ódio e horror, testemunha a verdade que é Deus.

Então, o que é a 'mãe'? A mãe é uma sedutora que nos tenta em direção a Deus, ela é até o próprio Deus. Ela está bem consciente de que é o único caminho pelo qual alguém é seduzido para a Verdade Mais Alta, é o caminho da sensualidade. E esse caminho deve levar ao desarranjo. Seu amor é cruel, ela não se perde, mas desencaminha a outra parte, leva-a à fronteira da destruição. Chicoteando-os sem piedade, ela exige severamente deles a última excitação de seus desejos, sejam eles da carne ou do espírito.

"Você ainda não sabe o que eu sei". As palavras que a mãe fala ao filho - o qual em seu último suspiro, atormentado pela verdade que ele acabou de descobrir sobre a corrupção de sua mãe - são evidentemente palavras de Deus.

De um outro ponto de vista, porém, Deus é um ocioso, uma prostituta imóvel deitada na cama. É sempre o humano que é forçado a trabalhar, forçado a fazer esforços, a ser derrubado. Nenhum romance que tente representar o lado de Deus pode ser mais do que um fragmento de desespero sutil, no qual há o amor misturado a uma frustração intelectual diante do absurdo do homem (seu filho). Deus é como um hipopótamo, imóvel na lama tropical: "Sua mãe está em paz no lodo".

Bataille mostra desapaixonadamente que a negação de Deus pelos homens, o grito desesperado de negar a existência de Deus, de fato, "não vem do seu verdadeiro coração". Esse "coração verdadeiro" incorpora o âmago do que chamamos de "erotismo" de Bataille. Afinal, não foi graças a ele que esse abismo de erotismo nos foi aberto, um abismo que um certo psicanalista vienense comum era evidentemente incapaz de explorar? 
No entanto, como eu disse anteriormente, Bataille nunca deixa de entrar neste romance metafísico erótico, com bem planejados 'procedimentos psicológicos' que são centrais para o romance. De fato, só pode ser um romancista psicológico que pode fazer a mãe 'não sentir paz em sua alma até depois de ter feito seu filho inocente arrumar a mesa do pai morto para encontrar uma coleção de fotografias pornográficas e prever seu desgosto. "Ela podia compartilhar dessa repulsa com o filho para que essa emoção compartilhada a levasse a um estado de loucura".

É uma consequência imediata que a ternura transborde como mel; como uma onda, o amor nasce com sofrimento compartilhado e doce beleza, da qual uma crueldade surgirá.

E, a fim de preparar cuidadosamente o desenlace do romance, o ato incestuoso consumado entre mãe e filho, o escritor deliberadamente revela o resultado - o suicídio da mãe - e sugere que o suicídio provém tanto do remorso pela situação em que, eventualmente, ela não teve escolha a não ser convidar o filho para a cama, como por desespero: "Eu não desejava minha mãe, ela não me desejava”. Isso, aliás, não passa de uma análise psicológica, um procedimento para convencer o leitor. Isso é suficiente como um delineamento psicológico para um romance. No entanto, como não era intenção do escritor representar uma mera tragédia psicológica pessoal, ele deliberadamente avisa o leitor para que, assim que tenha certeza do final, Bataille esteja preparado para empurrar o leitor para o incesto espiritual e intelectual entre mãe e filho, o que é, em última análise, mais horripilante, mais sensual e mais "corrupto" do que o incesto físico.

A própria mãe diz: “o prazer da mente, mais sujo que o do corpo, é mais puro e o único cuja borda nunca fica entorpecida. O vício, na minha opinião, é como o brilho escuro da mente que cega e do qual estou morrendo. A corrupção é o câncer espiritual reinando nas profundezas das coisas".

O que era 'homem' para ela, um discípulo de Safo?

“Um homem nunca ocupou seus pensamentos, nunca penetrou, exceto para saciar seu deserto onde ela queimava, onde seu desejo parecia ser, junto com ela, a beleza silenciosa de pessoas anônimas e indiferenciadas que sofriam uma destruição desagradável. Nesse reino de luxúria, não havia espaço para ternura: os gentis e amorosos foram banidos deste lugar, 
descritos nas palavras do evangelista: Violenti rapiunt Illud ${ }^{4}$. Minha mãe me destinou à violência sobre a qual ela reinava".

Essa confissão final no romance Minha mãe é um solilóquio horrivelmente tenso. No entanto, não vou citá-lo aqui, pois sua verdadeira profundidade só fala da emoção de alguém que leu o livro inteiro.

\section{Referências}

ANGÉLIQUE, Pierre (pseudônimo de G. Bataille). Divinus Deus. Paris: Editions du Solitaire, [1937] 1941.

BATAILLE, Georges. O Erotismo. Trad. Fernando Scheibe. Belo Horizonte: Editora Autêntica, 2014.

BATAILlE, Georges. História do Olho. Trad. Eliane Robert de Moraes. São Paulo: Cosac Naify, 2003.

MISHIMA, Yukio. Georges Bataille and Divinus Deus. In: BATAILLE, Georges. My Mother, Madame Edwarda, The Dead Man. Nova York: Penguin Classics, 1976, pp. 11-21.

MISHIMA, Yukio. Patriotismo. In: MISHIMA, Yukio. Morte em pleno verão e outras histórias. Tradução de Aulyde Soares Rodrigues. Rio de Janeiro: Rocco, [1966] 1987.

MISHIMA, Yukio. Confissões de uma máscara (Kamen no Kokuhaku). Trad. Jaqueline Nabeta. São Paulo: Companhia das Letras, [1949] 2004. 